DOI: https://doi.org/10.47405/aswj.v6i1.160

\begin{tabular}{|c|}
\hline $\begin{array}{c}\text { ASIANSOCIAL WORK } \\
\text { JOURALL } \\
\text { (ASW) }\end{array}$ \\
Volume 6, Issue 1, February 2021 \\
e-ISSN : 0128-1577 \\
Journal home page: \\
www.msocialwork.com \\
\hline
\end{tabular}

\title{
Resiliency for Independent Living of Veterans with Disabilities
}

\author{
L. R. Abeywickrama ${ }^{1}$, H. M. S. Niroshani ${ }^{1}$ \\ ${ }^{1}$ National Institute of Social Development, Sri Lanka
}

Correspondence: L. R. Abeywickrama (ruchirangaa@gmail.com)

\begin{abstract}
This paper reports on a thematic analysis focusing on the perspective of veterans regarding social pressure experienced after the disability. The veterans returned from the battlefield, disabled, resented, and traumatized. They were eventually required to adopt with unanticipated lifestyle changes. This had life-long effects on the veterans along with the struggle of coping with societal demands. In this milieu, this study aims to identify the external constraints experienced by veterans with disabilities to lead independent lives. In addition, the focus on the existing resilience among veterans also is specified in the study. To garner information, ten in-depth interviews are conducted with selected male veterans in a rehabilitation center in Sri Lanka. The study identified unhealthy relationship patterns developed between veterans and their intimate family members as one of the constraints for veterans to lead an independent life. Changes in roles and responsibilities within the family, lack of attention from the partner, infidelity, lack of emotional attachment with children are identified as type of disruptive relationship patterns experienced by veterans after their disability. Lack of social acceptance on the other hand lessen the scope of veterans with disabilities to carry out independent lives. Labelling, exclusion from community activities, unrealistic demands to perform life tasks as exactly as before are recognized as data related to decreased social acceptance. Lifestyle changes in terms of having to adopt to a daily schedule, limited access to realize personal preferences are perceived as challenges to lead independent lives. Lack of self-esteem among veterans with disabilities has diminished their potential to bounce back from the adversity. The need of augmenting resilience skills of veterans with disabilities is therefore recommended in this study.
\end{abstract}

Keywords: veterans with disabilities, resilience, independent life

\section{Introduction}

Sri Lanka's present is haunted by the unpleasant memories of conflict between the Sri Lankan government and the Liberation Tigers of Tamil Ealam (LTTE), which required to create an independent state for ethnic minority Tamils. The war has lasted nearly three decades and is one of the longest running civil wars in Asia. This conflict had taken a heavy humanitarian toll, killing over 100,000 and displacing nearly 190,000 civilians (UN, 2009). The veterans have undergone a series of terrible physical, emotional, and life-threatening experiences in the battlefield. Most of the high incidence of injuries resulted in frequent suicide bombings and the use of heavy weapons (Gunawardena, 2010). Although the numbers of total impaired veterans in the country differ from each study, the impact of the disability have significantly affected their well-being and overall living conditions at a higher level. For veterans with disabilities, the traumatic experience become daily facts of their life. When they become 
DOI: https://doi.org/10.47405/aswj.v6i1.160

less independence, or feel that they cannot live fully, issues may arise. A study has been conducted on mental impacts of injuries including war induced PTSD (Post Traumatic Stress Disorder) and investigation of therapeutic and cultural healing process (Abeyasinghe et al., 2012; De Zoysa \& Wickrama, 2011; Gunawardena, 2007). On the other side, there was an emerging literature focused on using a gendered and embodied perspective to perceive impairments among veterans. (De Mel 2007, 2016; Gunawardena, 2010; Weisdorf, 2015). Mental Problems of Disabled War Heroes was given focused in another study conducted in a rehabilitation center in Sri Lanka (Padmasiri, 2014). Nevertheless, in the context of studies related to veterans with disabilities in the country and the hindrances for their independent living, there has so far been limited studies conducted. Therefore, conducting a study to delve into this phenomenon has been identified as timely relevant. Identifying the perception of veterans with disabilities in relation to the social pressure they experienced after the disability was taken as the research question of this study. It is imperative, to distinguish the perspective of veterans about their social environment and their shortcomings to embrace an independent life from the general societal view about them and their disability. Hence, identifying the external constraints to lead independent lives for veterans with disabilities and to explore the existing potential of them to absorb negative feelings while incorporating them in more efficient practices are taken as primary objectives of the study.

\section{Methodology}

This study was carried out in 2016 at a rehabilitation center for veterans with disabilities in Sri Lanka. A phenomenological approach was used in this study with the aim of using firsthand experience of veterans in relation to their experience of living with a disability and constructing a universal meaning to the phenomenon of independent living for veterans with disabilities with a more profound understanding. Phenomenology is an approach to qualitative research that focuses on the commonality of a lived experience within a particular group. The fundamental goal of the approach is to arrive at a description of the nature of the particular phenomenon (Creswell, 2013). Qualitative thematic methodology was used to form an in-depth understanding of the external constraints for the independent living of veterans with disabilities and to identify the existing capacity of veterans with disabilities to absorb negative feelings while integrating them in positive ways. Purposive sampling method was adopted to identify and select information-rich cases related to independent living for veterans with disabilities. As a tool of data collection, 10 in depth interviews were carried out with married male veterans who underwent a battlefield injury resulting in spinal cord injury, amputation of an upper limb, a lower limb. The male veterans were between the ages of 25-49. The exclusion criteria of sample selection were veterans with head injuries and veterans who were diagnosed to have a psychiatric disorder. Possible cognitive impairments among these veterans was the reason for exclusion from the research sample. Respondents were informed about the aim of the study prior to the data collection and interviews were carried out between 45-60 minutes. After a thorough familiarization of collected data, codes were generated. Through the codes, the themes were identified and analyzed.

\section{Result}

The thematic analysis process that was applied to the transcripts drew major findings and they were apparent in the data. These themes are perceived as essential in determining the objectives of the study. The main themes are categorized as "Unhealthy relationship patterns adopted by veterans with their family members", "Lack of social acceptance", "Lifestyle changes", "Unsecure thoughts about future", and "Low self-esteem". During the process of data analysis, the researchers identified some aspects of participant's responses that overlap across these themes. Nevertheless, it should be perceived as valid interpretation of data in general as all the themes are never made up of isolated concepts but are all relative to each other. 


\section{Unhealthy intimate relationship patterns with family members after the disability}

This theme was identified as one of the constraints for the independent living of veterans with disabilities. The disruptive nature of the unhealthy relationship maintains with family members have an influence on veteran's thinking and it has subsequently affected their behaviour. As Table 1 indicates, the primary theme connects two subthemes generated from five distinct codes. Sub themes are unhealthy relationship patterns with spouse and unhealthy relationship patterns with children.

Table 1: Unhealthy intimate relationship patterns with family members after the disability

\begin{tabular}{lll}
\hline Primary Theme & Sub Themes & Codes \\
\hline & Relationship with spouse. & $\begin{array}{l}\text { Shift in roles and } \\
\text { responsibilities. } \\
\text { Infidelity. }\end{array}$ \\
$\begin{array}{l}\text { Unhealthy relationship } \\
\text { patterns with the family } \\
\text { members }\end{array}$ & $\begin{array}{l}\text { Relationship with } \\
\text { children. }\end{array}$ & $\begin{array}{l}\text { Lack of attention from the } \\
\text { spouse. }\end{array}$ \\
& $\begin{array}{l}\text { Lack of engagement in } \\
\text { parenting. }\end{array}$ \\
& Lack of emotional \\
& attachment from children. \\
\hline
\end{tabular}

The following excerpt from in depth interview (03) illustrates the impact of the shift taken place in roles within the family on the independent living of veterans with disabilities.

"When I go home for the short stay, I see how my wife has taken my role in the family. When I went home last time, my wife has decided to change my child's school and she didn't even ask me anything about that, I just didn't know how to address that problem anymore.".

As key informant (10) stated "Now I have to depend on my wife, she decides my life, not me, and I don't know if I could be the same person who I used to be inside that house".

As per the respondent (04) "I used to communicate with the three-wheeler driver who takes my children to school, he used to call me to remind me about the hire and all. He now deals with my wife, and I don't know anything about that anymore".

This shift of roles taken place within the family units of veterans with disabilities, has left feelings of fear, threat among the veterans. "My wife started working, she earns more than my pension, and I am afraid if she leaves me" said by the key informant (07).

There might be a posed threat to men's masculine self-identity when wives' power in the marital relationship is exercised because of higher earning status of wives. (Hiller \& Philliber, 1986; Juster, 1985; Microwsky, 1987). The inability to adequately fulfil the role of breadwinner constitutes a significant site of anxiety for men in general and disabled men in particular. This is also the case for disabled soldiers of the Sri Lankan army even though they enjoy a regular salary until retirement, postretirement pensions and welfare provisions from the military. (de Mel, 2016: 101).

It is evident how infidelity have ruptured the marital relationship between veterans and their spouses. Consequently, veterans with disabilities struggle to maintain a supportive, empathic relationship with their partners.

Interview (01) "When I went home last month, one of my neighbours said that my wife is having an affair with another man in our village. I feel helpless. I can't do 
DOI: https://doi.org/10.47405/aswj.v6i1.160

anything with that. I really feel ashamed when that person was telling this right to my face".

(05) Respondent revealed what he heard from his friend about the wife. "My friend told me that my house is run by another man, and he was also a friend of mine. Can you imagine what I felt? Am I that powerless?" He stopped talking and took a deep breath with a long pause - Researcher's observation. It is found from this study that veterans with disabilities find it difficult to lead an independent life when they do not receive the expected attention from their partners.

Interview (10) - "My wife talks about Prasanna all the time, he is a businessman in our village, and I don't like him since then, my wife says that he is generous and being nice to her and my children. I don't like my wife talking about him all the time. That hurts me".

As respondent (02) "My wife calls me only when she needs to transfer my salary to the account. Otherwise, she doesn't talk. Even if I call, she ends the conversation very soon".

"When my wife came to stay over with me to the centre, she said that we should not have any sexual act and said that "you can't do all these now". I felt shame at that moment". - Respondent (06). Disabled soldiers worry about their marriage prospects or abandonment by their wives or girlfriends (de Mel, 2007: 108).

A significant distant from children was identified in this study and the veterans with disabilities have observed the changed behavior of their children over the time. This condition has left feeling of sadness and hopelessness among veterans with disabilities. It was also identified the less opportunity given to them to engage in parenting and it has resulted in feeling of incompetency.

According to the interview (09), "My children were sad when this happened to me and they were taking care of me really well. But now, I feel that they are not the same. They don't talk much even if I go home.".

As interviewee, (10) stated, "When my daughter came with my wife to visit me, she didn't talk with me. I tried to cuddle her, and she rejected me and cried."

Respondent (09) also said that he was not included in decision making about his daughter's marriage ceremony. According to him "I didn't know that they have arranged everything for my daughter's wedding, from finding the groom to everything was done by my wife and I wasn't asked to engage in any of these."

As more supportive data to this particular fact, interview (02) stated as this; "My children don't obey me anymore, my son one day told me that I don't have a right to control them, only mother can".

\section{Lack of Social Acceptance}

As table 2, sub themes such as lack of acceptance from friends, community and co-workers have analyzed using six identified codes to form the main theme. It was found how social acceptance is valued by veterans especially from their familiar social context. It was also expressed by the respondents about the importance of feeling accepted by their social environment in realizing the meaningful existences with and among others.

Table 2: Lack of social acceptance

\begin{tabular}{|c|c|c|}
\hline Primary Theme & Sub Themes & Codes \\
\hline & & $\begin{array}{l}\text { Lack of communication with } \\
\text { friends. }\end{array}$ \\
\hline
\end{tabular}


DOI: https://doi.org/10.47405/aswj.v6i1.160

\begin{tabular}{ll}
\hline \multirow{2}{*}{ Lack of social acceptance } & $\begin{array}{l}\text { Acceptance of friends } \\
\text { Acceptance of community } \\
\text { Acceptance of co-workers } \\
\text { (the staff of the centre) }\end{array}$
\end{tabular}

Exclusion from gatherings

with friends.

Perceive as "incapable".

Lack of empathic

understanding. Labelled as

"Rehabilitation people".

Pressure to perform tasks as before.

The stigma associated with the concept of "Rehabilitation" in the country was also highlighted by a respondent and according to him "When people see me coming home, they ask, oh! You are coming from rehabilitation? They think I am coming from drug or alcohol rehabilitation; they don't know what we do there in the rehabilitation centre". This explains how the existing "collective narratives" of the concept of 'Rehabilitation' has made a kind of social exclusion of veterans with disabilities.

Having the friends withdrawn also identified as a constraint for independent living of veterans with disabilities. As respondent (07) expressed, "I can't have new friends again, but my friends also not talking to me like before, maybe they are tired of talking to me about the same thing over

and over again". This statement illustrates, the diminished power of veterans with disabilities to choose new friends in their life and the disconnection of existing friendships.

It is also apparent in this study that veterans with disabilities have issues in relation to the acceptance from their co-workers. These co-workers also happened to be the staff of the rehabilitation centre.

According to the respondent (01), "The staff we have here worked with us in the battlefield, they think we are still capable and treat us in that way.".

Interview (04) “These people say that we shouldn't be weak like this, we should be able to strong and be normal like before".

Interview (06) "Co-workers don't understand us. They think we still should have military morale. They sometimes can't understand what we are really going through".

Interview (03) said "The staff sometimes say, oh you were in the battlefield, don't be weak, we are not taught to be weak". This indicates how military training has an impact on its' employee's perception on human qualities. In such an environment, veterans with disabilities struggle doubly. They become afraid to express their difficult emotions as there is no room for such emotions in the environment they live.

\section{Lifestyle Changes}

It is identified in this study the negative impact of unprecedented lifestyle changes happened for veterans with disabilities on their ability to lead independent life.

Table 3: Lifestyle Changes

\begin{tabular}{lll}
\hline Primary Theme & Sub Themes & Codes \\
\hline & Changed environment. & $\begin{array}{l}\text { Difficulty to adjust with } \\
\text { family environment. }\end{array}$ \\
Lifestyle changes & $\begin{array}{l}\text { Uncertainty about the living } \\
\text { environment } \\
\text { Changed way of living. }\end{array}$ & $\begin{array}{l}\text { Living according to a } \\
\text { timetable. }\end{array}$ \\
& \\
\hline
\end{tabular}


Less opportunities for personal preferences.

The disabilities have resulted in veterans being chairbound and therefore the activities of daily living have been limited too. Having to adopt to a new environment and to a new way of living have brought feelings of frustration, disappointment, and homelessness among them. This condition has left the veterans with disabilities "trapped in this life", as respondent (02) succinctly mentioned.

Proving this situation veteran (09) stated "Sometimes I don't feel certain about this environment. This is neither my home nor the battlefield".

It was also found that having to follow a timetable everyday has brought distress to veterans with disabilities. Interview (08), "I am tired of this now, every day the same routine, I don't have a freedom to live the life in the way I want. I 'll have to wake up not because I want to but because that's what timetable says, or the routine schedule says".

Lack of ability among veterans with disabilities to use the available resources within the centre also was found in the study. As respondent (04) indicated "We have all the facilities here, like in a hotel, but most of us don't know what to do with them, we still feel stuck here".

Uncertainty about their future also was expressed in many interviews. Most of them have uncertain thought about their children, marital relationship, and about themselves. Interview (05), "I don't know If my wife waits for me till I become independent again".

Interview (07), "I also think about children, but I don't know how they will treat me in future. I sometimes feel devasted when I think of this."

As respondent (04) said "I am really worried about my future, I don't know what is going to happen me".

\section{Lack of self-esteem}

Most of the veterans interviewed in this study have low self-esteem characteristics such as comparing themselves with co-workers, difficulty in trusting their own judgements, and feelings of inferiority.

As one of the veterans said "I don't like Jayantha at all, and I don't like to be treated by him. I feel incompetent when he provides his service to me".

Interview (01)- "That person and I worked together, and he recently got a promotion. I am just stuck in this wheelchair".

"Sometimes I can't take right decisions, maybe that's why my wife doesn't take my opinions anymore."- Interview (03).

"Maybe I am not enough for my wife, that's why she rejects me even when she comes to meet me here"- Interview (02)

All these identified dimensions of self-esteem are critical variables of decreased resilience among veterans with disabilities. They have lost the ability to bolster them up times of experienced trauma. It is evident that the disability has affected veterans differently, bringing a unique flood of thoughts, difficult emotions, and ambiguity which ultimately affects their personal growth and development. 
DOI: https://doi.org/10.47405/aswj.v6i1.160

\section{Conclusion and Recommendations}

This study focuses on identifying the barriers for independent living of veterans with disabilities in Sri Lanka and to identify their existing capacity to cope up with difficult emotions along with the ability to integrate them in a productive manner. Unhealthy relationships maintained with family members after the disability, feeling of isolation in the society, and unanticipated lifestyle changes have confined the ability of veterans with disabilities to lead an independent life. On the other hand, unsecure feelings about the future and decreased self-esteem have limited their resiliency skills to cope up with the trauma and consequently, most of these veterans need external support to enhance their potential to cope adaptively with difficult feelings allied with the traumatic event.

A discourse about the concept of resilience, especially in terms of promotion of the concept and mitigating possible risk factors for severe post-traumatic consequences among veterans with disabilities, should be encouraged among the civil society and the military sector of the country. While addressing this, it is vital to comprehend the complexity of the concept of resilience and its' possibility to exist in different degrees across various domain of individual life. It is therefore highly recommended to conduct more studies with the aim of contextualizing the concept of resilience to veterans with disabilities and to propose appropriately tailored tools and techniques to augment the resilience of veterans with disabilities in the country. More empirical data should be added to the existing literature to identify the perspectives of family members and communities of veterans with disabilities in relation to the changed behavior patterns and adopted coping strategies of veterans with disabilities.

Importance of adopting an integrative approach to serve veterans with disabilities should be identified by the policy makers and the relevant governing authorities of the country. Utilization of the services from disciplines such as Military Social Work, Psychotherapy and Counselling should be given consideration in the process of creating a better environment for veterans with disabilities to lead independent lives while enhancing their ability to bounce back from the stressors of the disability and the war related trauma. Military Social Workers and Counselors should be appointed in the work force to form assessments and interventions that could be drawn from a broad range of biological, psychological, and social theories related to post-war trauma and disability.

The military authorities should also continue collaborative work with National Institute of Social Development (NISD), the pioneer organization for Social Work education in Sri Lanka. Professional service from Social Work Practitioners, Social Work educators and Counselors could be taken to provide training and necessary knowledge to the existing staff of military sector in the country, especially to identify the psycho-social factors that hinder the ability of

independent living of veterans with disabilities and to teach resilience skills. In addition, the staff of the rehabilitation centres should be trained to improve their empathic skills, with the intention of relating well with veterans with disabilities. Furthermore, the service from these professionals should be taken to evaluate international and standard rehabilitation methods with the purpose of incorporating them in a contextually appropriate manner. Encourage volunteering, and placements among Social Work students to work with veterans with disabilities should be given consideration by NISD.

In addition, welfare facilities for families of veterans with disabilities should be strengthened and it should be the responsibility of the Ministry of Defense, Sri Lanka to launch more effective programmes and schemes in future.

\section{References}

Abeyasinghe, N. L., P. de Zoysa, K. M. K. C. Bandara, N. A. Bartholameuz, and J. M. U. J. Bandara. (2012). "The Prevalence of Symptoms of Post-traumatic Stress Disorder Among Soldiers with Amputation of a Limb or Spinal Injury: A Report From a Rehabilitation Centre in Sri Lanka." Psychology,Health \& Medicine 17 (3): 376-381. 
Creswell, J.W. (2013). Qualitative Inquiry \& Research Design: Choosing Among the Five Approaches. Thousand Oaks, CA: SAGE Publications, Inc. (pp. 77-83).

De Mel, Neloufer. (2007). Militarizing Sri Lanka: Popular Culture, Memory and Narrative in Armed Conflict. New Delhi: Sage.

De Mel, Neloufer. (2016). "Playing Disability, Performing Gender: Militarised Masculinity and Disability Theatre in the Sri Lankan War and Its Aftermath." In Disability in the Global South: International Perspectives on Social Policy, Administration, and Practice, ed. Shaun Grech and Karen Soldatic, 99-116. Geneva: Springer.

De Zoysa, Piyanjali, and Thulitha Wickrama. (2011). "Mental Health and Cultural religious Coping of Disabled Veterans in Sri Lanka.” Journal of Military and Veterans' Health 19 (3): 4-12.

Gunawardena N. (2010). Subverted Heroes: Narrative Experiences of Disabled Veterans in Post-War Sri Lanka. MA Thesis, The School of Sociology and Social Policy, The University of Leeds. 1415.

Hiller, Dana V., and William W. Philliber. (1986). "The Division of Labor in Contemporary Marriage: Expectations, Perceptions, and Performance." Social Problems 33:191-201.

Honneth, Axel. (1995). Struggle for Recognition: The Moral Grammar of Social Conflicts. Cambridge, MA: MIT Press.

Litz BT, Steenkamp MM, Nash WP. (2014). Resilience and recovery in the military. In Facilitating resilience and recovery following trauma (eds Zoellner LA, Feeny NC.), pp. 113-136. New York, NY: Guilford Press.

Padmasiri, M.K.D. (2014). Mental Problems of Disabled War Heroes: With Special Reference to Rehabilitation Organization. International Journal of Scientific and Research Publications 4(5), $1-3$.

Seligman ME, Fowler RD. (2011). Comprehensive soldier fitness and the future of psychology. Am. Psychol. 66, 82-86. (10.1037/a0021898).

United Nations. (6 May 2009). Sri Lanka's displaced now numbers over 192,000, UN reports. Available: Sri Lanka's displaced now numbers over 192,000, UN reports || UN News.

Weisdorf, Matti. (2015). "Hope of Deliverance: An Ethnography of Disability, Social Recognition and the Work of Hope Among War-Impaired Veterans in Sri Lanka." MA, University of Copenhagen. 